\title{
Improving the Efficacy of Cisplatin using Niosome Nanoparticles Against Human Breast Cancer Cell Line BT-20 : An In Vitro Study
}

\author{
Leila Kanaani ${ }^{1}$, Maral Mazloumi Tabrizi², Azim Akbarzadeh Khiyaviª ${ }^{3}$ Iraj \\ Javadi $^{4}$
}

${ }^{1}$ Department of Toxicology, Faculty of Pharmacy, Islamic Azad University, Shahreza Branch, Isfahan, Iran. ${ }^{2}$ Department of Toxicology and Pharmacology, Pharmaceutical Sciences Branch, Islamic Azad University, Tehran, Iran. ${ }^{3}$ Department of Pilot Nanobiotechnology, Pasteur Institute of Iran, Tehran, Iran. ${ }^{4}$ Department of Toxicology, Faculty of Pharmacy, Islamic Azad University, Shahreza Branch Isfahan, Iran.

\begin{abstract}
Objective: Today, cancer is one the most important challenges in modern medicine. Meanwhile, breast cancer is one of the most common causes of mortality among cancers. The initial response to the treatment and then becoming resistant to the cisplatin is one of basal challenges of treatment of breast cancer. Recently, using nanotechnology including drug nanocarrier named niosome can decrease adverse effects and increase the efficiency of treatment. Material and Methods: The aim of this research was to investigate using niosome nanoparticles containing cisplatin and investigation of their lethal effect on breast cancer cell line. Results: We found that using niosome nanoparticles can provide a suitable formulation of cisplatin drug. Conclusion: The efficiency of nanoniosome cisplatin was more than free drug, decreasing the administered dose and therefore the damage to other tissues
\end{abstract}

Keywords: Breast cancer- Cisplatin- Nanoniosome

Asian Pac J Cancer Biol, 2 (2), 27-29

\section{Introduction}

Cancer starts when cell mutates in the growth controlling genes. In the natural modes, if cell mutates irreparably, it will kill himself but if it can't kill itself, the cell and/or its progeny and lineage may divide uncontrollably with wrong genetic information [1]. Recently, nanotechnology allows targeted treatment to reduce adverse effects of drugs and increase their efficiency. Nanoscale drug carriers are capable of overcoming biological barriers and enhance drug release. Niosome is a kind of nanoscale drug carrier [2]. Niosomes are non-ionic surfactant vesicles whose vesicle system can be used as carriers of lipophilic and amphiphilic. Theirs non-ionic property leads to less toxicity and limited reaction with cell, increasing the therapeutic index of encapsulated drug [3].
Submission Date: 02/14/2017Ａcceptance Date: 05/25/2017

\section{Materials and Methods}

\section{Materials}

Span60, cholesterol, Polyethylene glycol 3350, cisplatin, human breast cancer cell line BT-20 were used.

\section{Preparation of nanoparticles containing drug}

At first span 60, cholesterol, and polyethylene glycol 6,000 were mixed in diethyl ether. The solvent was evaporated using rotary evaporator in $90 \mathrm{rpm}$ and at $45^{\circ} \mathrm{C}$. The thin film formed at the bottom of round bottom flask was then hydrated by PBS containing cisplatin $(1 \mathrm{mg} / \mathrm{ml})$ and stirred. The final concentration was calculated 7, 4, 1 , and $3.3 \mathrm{mM}$ respectively. To provide smaller and more homogenized particles, they were sonicated using bath sonication for $10 \mathrm{~min}$. Blank nanoparticles were prepared with the abovementioned method without the drug. 


\section{Morphological evaluation of nanoparticles}

Size, shape, and probable crystallization of constructed niosomal nanoparticles were evaluated using light microscopy.

\section{MTT test}

MTT test was used to investigate cytotoxicity of the formulation containing cisplatin and its effect was compared with that of standard drug.

\section{Statistical analysis}

Obtained data were analyzed by SPSS (version 16). In addition, all stages of toxicity were analyzed by Pharm software.

\section{Results}

\section{Morphological evaluation}

Light microscopy revealed the niosomal nanoparticles as hollow spherical to ellipsoid configuration that dispersed in the matrix (Figure 1).

\section{Cytotoxicity}

The results of the cytotoxicity tests of nano-cisplatin and free drug are summarized in Table 1. Control nanoparticles were devoid of toxicity, even at high concentrations. IC50 was reported in micromolar. Results showed that nano- conjugated cisplatin was more cytotoxic than cisplatin. In other words, IC50 was less in nano-conjugated cisplatin than cisplatin.

\section{Discussion}

Among different chronic and infectious disorders, such as diabetes and metabolic syndrome and etc [4-9], cancer has always been the most significant [7-10]. Nanotechnology is being used for the treatment of

Table $1 . \mathrm{IC}_{50}$ Cytotoxicity of Nano-Conjugated Cisplatin, Free Cisplatin, and Control Group At front Side Category Of Cell Cancer the Breast In Vitro Human

\begin{tabular}{ccc}
\hline BT-20 (Control & BT-20 (Free Drug) & BT-20 (Nano Drug) \\
Drug) $\mathrm{IC}_{50}(\mu \mathrm{M})$ & $\mathrm{IC}_{50}(\mu \mathrm{M})$ & $\mathrm{IC}_{50}(\mu \mathrm{M})$ \\
\hline $164.1 \pm 16.0$ & $135 \pm 8.8$ & $92 \pm 4.7$ \\
\hline $\mathrm{IC}_{50}$ (in terms of $\left.\mu \mathrm{M}\right)$ shows the average result from three experiments.
\end{tabular}

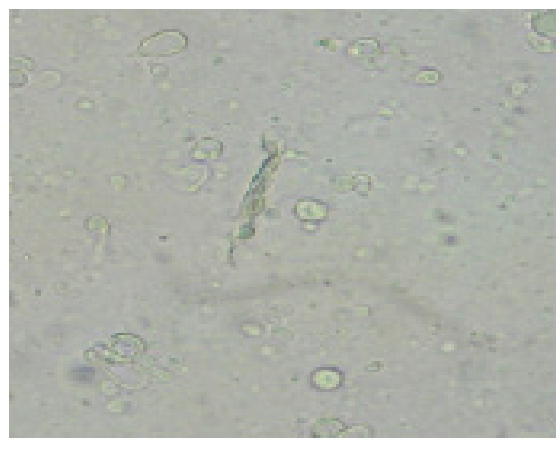

Figure 1. Light Microscopy of Cisplatin Loaded Pegylated Niosomal Nanoparticles different diseases. Nanoparticulate drug delivery system supplies several benefits compared to conventional drug delivery system [11]. Nanoparticles have several uses, such as medicine and industry [12-13]. Different nanoparticles are used in drug delivery, for instances, liposomal nanoparticles. Niosomal nanoparticles and Nano-Poly Butyl Cyanoacrylate [14-17]. The chemotherapy and herbal agents impactson cancer cells were investigated in former researches [16-20].This study reported that the niosomal formulation could be one of the promising delivery systems for the breast cancer treatment by using drug silymarin. Reverse phase evaporation technique was a suitable method for preparation of cisplatin loaded niosomal nanoparticles which was confirmed by appropriate properties of nanoparticles. PEG was applied in this investigation due to its proper stability in blood circulation, low immunogenicity, water solubility, and antigenisity along with its capability to extend the period of drug release [21]. Drug release is a strongly influence factor in drug delivery systems [22]. In this research, a sustained release of cisplatin from nanoparticles was also perceived.

In conclusions, nanoniosomal cisplatin had higher efficiency than free cisplatin in destructing breast cancer cells. This fact may be due this fact that the nanoniosomal drug has a amphipathic structure like the bilayer structure of a breast cell line membrane and can easily penetrate to tumour and release the nanomedicine directly into the target cell, causing the death of BT-20 cell line.

\section{References}

1. Blagosklonny MV. A node between proliferation, apoptosis and growth arrest. Bioessays, 1999; 21(8): 704 - 9.

2. Mozafari M.R. Nanocarrier Technologies: Frontiers of Nanotherapy springer, 2006; 237: $1-12$.

3. pawar SD, pawarrg, kodag PP, waghmare AS, gadhaveMV, jadha Vslandgaikwad DD: Niosome: An U nique Drug Delivery System IJBPAS, 2012; 1(3): 406 - 416.

4. Ebrahimi Far M, Mazdapour M, Kaki A, Mohammadi P, et al . Comparison of Biochemical Factors and Liver Enzymes in type 2 Diabetes Patients and Healthy Individuals. Bull EnvPharmacol Life Sci,2015.4, 1-4.

5. Goodarzi MT, Mohammadian M, BorzoueiSh,et al . Association between Plasma Cholesteryl Ester Transfer Protein activity and Lipid profiles in Metabolic Syndrome in an Iranian Population.Int Res J Biological Sci,2014...3;89-90.

6. Mohammadian M, Toofani Milani A, Hassas M R,et al . Evaluation of Serum Iron, Zinc and Their Relationships with Glycemic Control Status in Iranian Elderly Women with Type 1 Diabetes Mellitus. Journal of Pharmacy and Pharmacology,2015. 3;411-416.

7. Mohamadi N, Mohammadian M, Toofani Milani A, et al - Toxicity of cisplatin-loaded poly butyl cyanoacrylate nanoparticles in a brain cancer cell line: Anionic polymerization results. Asian Pac J Cancer Prev,2017. 18, 629-32.

8. Rostamzadeh Z, Mohammadian M, Rostamzade A. Investigation of Pseudomonas aeruginosa Resistance Pattern against Antibiotics in Clinical Samples from Iranian Educational Hospital. Adv Microbiol;2016.6(3),190-194.

9. Rostamzadeh Khameneh Z, Mohammadian M, Nemati M, Rostamzade A. Investigation of Herpes Simplex 
Virus-2 (Hsv-2) Infection in Coronary Artery Disease Patients (CAD) in Population from Iran. Advances in Bioresearch.2015.6,74-78.

10. Ebrahimi Far M, HasanzadeGanroudsari M, Kazemi M, et al . Enhancing Effects of Curcumin on Cytotoxicity of Paclitaxel, Methotrexate and Vincristine in Gastric Cancer Cells.Asian Pac J Cancer Prev, 2017. 18, 65-68.

11. Chidambaram, M. and K. Krishnasamy, A Step-by-Step Optimization Process to Fabricate Narrow Sized Dual Drug Loaded Polymeric Nanoparticles Using Modified Nanoprecipitation Technique. Nano Biomedicine \& Engineering, 2013. 5(3).

12. Mohammadi H, Abedi A, et al. Evaluation of synthesized platinum nanoparticles on the MCF-7 and HepG-2 cancer cell lines. International Nano Letters. 2013;3(1):1-8.

13. Izadi M, Ebrahimi Far M, Kanaani L, et al. Remove Nickel (II) From Drinking Water Using Thiol-Functionalized Chitosan. Advanced Biomedical Research, 2016. 7, 107-112.

14. Khalili M, Akbarzadeh A, et al. The effect of nanoliposomal and PE gylated nanoliposomal forms of 6-gingerol on breast cancer cells. Research Journal of Recent Sciences. 2009;2277:2502.

15. Esfahani MKM, et al. Pegylation of nanoliposomal paclitaxel enhances its efficacy in breast cancer. Tropical Journal of Pharmaceutical Research. 2014;13(8):1195-8.

16. Ahmadi L, Chiani M, et al. To evaluate the effect of formulation of Nanoarchaeosomal 6-gingerol on the growth of breast cancer MCF-7 cell line. New Cellular and Molecular Biotechnology Journal. 2015;5(19):47-52.

17. Rostaminasab S, Toofani Milani A, Mohammadian M, et al . Antitumor Immunostimulatory Effect of Sitosterol from Salvia atropatana on Tumor bearing mice. Adv Biores,2015.6, 133-40.

18. Sajjadiyan SZ, Toofani Milani A, Mohammadian M, et al. Preparation of silibinin loaded pegylatedniosomal nanoparticles and investigation of its effect on MCF-10A human breast cancer cell line. Der Pharm Lett, 2016.8 , 70-5.

19. Zarei M, Norouzian D, Chiani M, Ebrahimi H, Mohammadi M, Akbarzadeh A. Advantages of paclitaxel-loaded nano niosomes to nanoliposomal formulation: an in vitro study. Int J Life Sci Bt \& Pharm Res. 2013;2:335-42.

20. Dadgar N, Alavi E, Moftakhari Esfahani M, et al. Evaluation the cytotoxicity of nanoliposomal artemisinin on breast cancer cell line. New Cellular and Molecular Biotechnology Journal. 2014;4:99-103.

21. Shahbazian, S., et al. Anti -cancer activity of pegylated liposomal trans-anethole on breast cancer cell lines MCF-7 and T47D. Biotechnology letters, 2015. 37(7): p. 1355-1359.

22. Barzegar-Jalali, M., et al. Kinetic analysis of drug release from nanoparticles. Journal of Pharmacy and Pharmaceutical Sciences, 2008. 11(1): p. 1

\section{(i) $\$$}

This work is licensed under a Creative Commons AttributionNon Commercial 4.0 International License. 